NBER WORKING PAPER SERIES

\title{
PATTERNS OF SKILL PREMIA
}

\author{
Daron Acemoglu
}

Working Paper 7018

http://www.nber.org/papers/w7018

\author{
NATIONAL BUREAU OF ECONOMIC RESEARCH \\ 1050 Massachusetts Avenue \\ Cambridge, MA 02138 \\ March 1999
}

I thank Ali Burak Guner for research assistance, Joshua Angrist and Jaume Ventura for comments, and the NSF for financial support. The views expressed in this paper are those of the authors and do not reflect those of the National Bureau of Economic Research.

(0) 1999 by Daron Acemoglu. All rights reserved. Short sections of text, not to exceed two paragraphs, may be quoted without explicit permission provided that full credit, including ${ }^{\circledR}$ notice, is given to the source. 
Patterns of Skill Premia

Daron Acemoglu

NBER Working Paper No. 7018

March 1999

JEL No. O14, O33, J31

\section{ABSTRACT}

In this paper, I develop a model to analyze how skill premia differ over time and across countries, and use this model to study the impact of international trade on wage inequality. Skill premia are determined by technology and the relative supply of skills. An increase in the relative supply of skills, holding technology constant, reduces the skill premium. Among countries sharing the same technology, those with greater supplies will therefore have lower skill premia. An increase in the supply of skills over time, however, induces a change in technology, increasing the demand for skills. As a result, the relationship between relative supplies and skill premia over time may be increasing. Similarly, across countries developing their own technologies, there need not be a decreasing relationship between relative supply and skill premia.

Holding technology constant, an increase in the volume of international trade increases the skill premium in countries where skills are abundant, and reduces it in skill-scarce countries. Trade also induces skill-biased technical change, creating a powerful force towards higher skill premia in both skill-abundant and skill-scarce countries. As a result, trade opening can cause a rise in inequality in the U.S. and the LDCs, and thanks to the induced skill-biased technical change, this can happen without the usual intervening mechanism of standard trade models, a rise in the relative prices of skill-intensive goods in the U.S.. I also show that an increase in the volume of trade, while increasing skill premia in skill-scarce countries and the technological leader, the U.S., may actually reduce skill premia in medium skill, European, countries.

Daron Acemoglu

Dept. of Economics, E52-371

Massachusetts Institute of Technology

50 Memorial Drive

Cambridge, MA 02142

and NBER

daron@mit.edu 


\section{Introduction}

Figure 1 plots the relative supply of graduate equivalent workers and the college premium in the U.S. between 1949 and 1995. ${ }^{1}$ Despite the large increase in the supply of college graduates over the past 45 years, the college premium has not fallen. Rather, it has increased from $37 \%$ in 1949 to $62 \%$ in 1995.

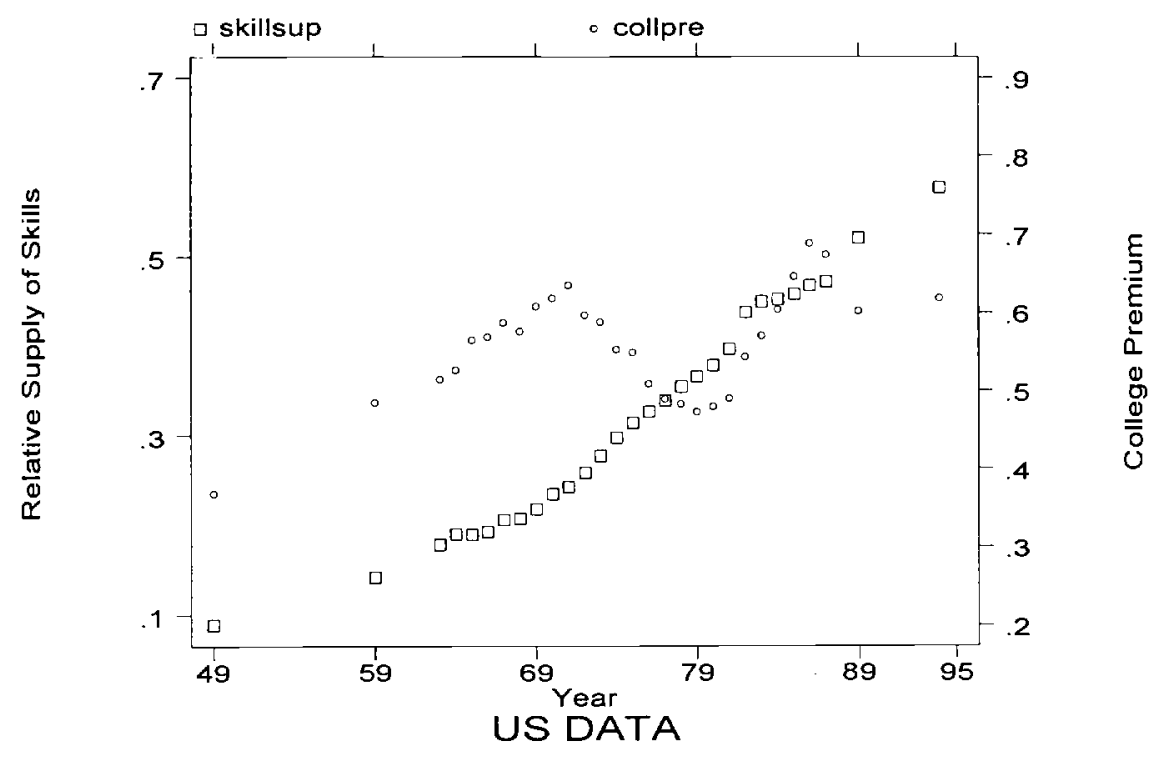

Figure 1: Relative supply of college equivalent workers and the college premium in the U.S. 1949-1995.

Figure 2 plots the average years of secondary schooling and percentage returns to schooling across 42 countries. ${ }^{2}$ Although data quality is an issue in many cases, the

\footnotetext{
${ }^{1}$ This figure plots the 25 years of data used by Katz and Murphy [1992] from the CPS and the data reported by Autor, Katz and Krueger [1998] from the censuses of 1950, 1960, 1990 and CPS 1996. The relative supply of college equivalents is constructed as in Katz and Murphy [1992, p.68]. It is equal to college graduates $+0.29 \times$ some college- $0.05 \times$ high school dropouts divided by high school graduates $+0.69 \times$ some college $+0.93 \times$ high school dropouts. I left out the data from the 1940 census because college premium appears to be suspiciously high in 1940 at $50 \%$. In fact, there are a number of problems with this cenus. First, the education variable is different (attendance rather than completion). Second, interviewing methods were different which, Goldin [1994] argues, led to substantial overstatment of years of schooling, possibly by as much as a factor of 1.5 or 2 for some cohorts. Third, this was the first census in which income data were collected and the inexperience of the interviewers led to many mistakes. Finally, there was no self-employment income in this census and a large fraction of the population were self-employed.

${ }^{2}$ The returns data are from the survey by Psacharopoulos [1994] and years of secondary schooling $n$
} 


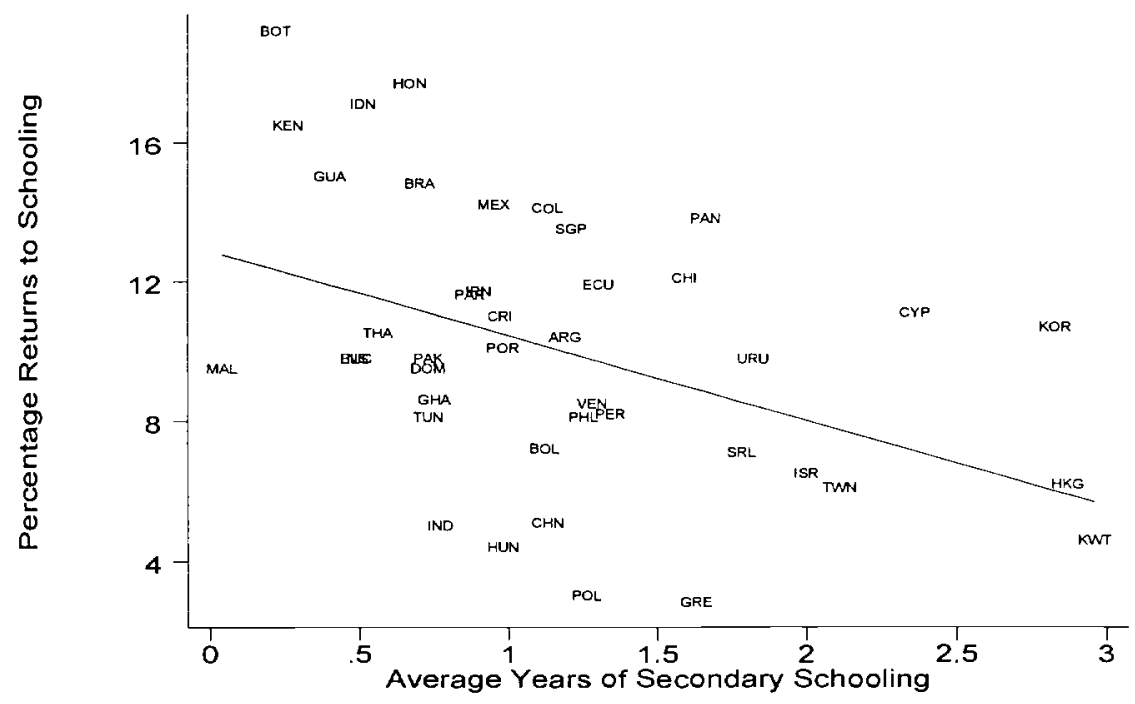

Figure 2: Returns to schooling and average years of secondary schooling for "technological followers".

figure shows a well-defined negative relation, with a coefficient of -2.43 and standard error 0.80 . What explains the different patterns of skill premia over time and across countries?

In this paper, I develop a framework to analyze this question. Skill premia are determined by the relative supply of skilled workers and the degree of skill bias of technology. Building on Acemoglu [1998], I endogenize the skill bias of technology as a function of the relative supply of skilled workers and the relative prices in the economy. Given the equilibrium skill bias, the skill premium is declining in the relative supply of skills as indicated by the constant technology relative demand curve CT in Figure 3. An increase

1985 are from the Barro-Lee data set (http://www.worldbank.org/html/prdmg/grthweb/ddbarle2.htm, see also Barro and Lee [1993]). Return to schooling is the schooling slope coefficient from micro data log wage regression on schooling, potential experience and potential experience squared for each country. The results should be interpreted with caution as data quality differ across countries and refer to different dates for different countries. The countries are Argentina, Bolivia, Bostwana, Brazil, Chile, China, Colombia, Costa Rica, Cyprus, Dominican Republic, Ecuador, El Salvador, Ghana, Greece, Guatemala, Honduras, Hong Kong, Hungary, India, Indonesia, Iran, Israel, Kenya, South Korea, Kuwait, Malaysia, Mexico, Nicaragua, Pakistan, Panama, Paraguay, Peru, the Philippines, Poland, Portugal, Singapore, Sri Lanka, Taiwan, Thailand, Tunisia, Uruguay, Venezuala. Using different measures of skill supplies, such as average years of schooling or ratio of workers with secondary (completion or attendence) to those without, leads to very similar results. 


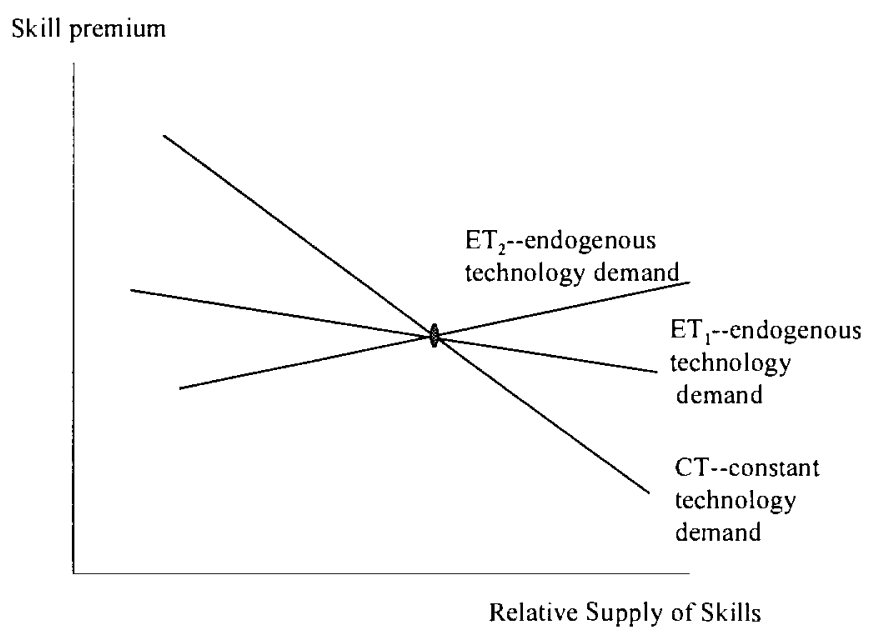

Figure 3: Relative demand for skills.

in the relative supply of skills also induces skill-biased technical change, increasing the demand for skills. Therefore, the relative demand for skilled workers will be typically more elastic when technology adjusts to changes in supply, as shown by the curve $\mathrm{ET}_{1}$. When the impact of supply on technology is powerful, the relation between relative supply and relative price of skills may even be increasing as shown by the curve $\mathrm{ET}_{2}$ in Figure 3. A possible explanation for the pattern in Figure 1 is therefore a steadily increasing supply of college graduates in the U.S., inducing the development of more and more skill-biased technologies, and moving the economy along the curve $\mathrm{ET}_{2}$.

Cross-county patterns, on the other hand, depend on whether technologies are determined locally or globally. The countries depicted in Figure 2 are technological followers, typically using U.S. technologies. Hence, variations across these countries will be traced by the constant technology curve $\mathrm{CT}$, and the relationship between skill supplies and premia across these countries will be decreasing.

This argument does not extend to comparisons across countries developing their own technologies. Figure 4 plots returns to schooling and average years of schooling among technologically more advanced countries, ${ }^{3}$ and shows that there is no well-defined

\footnotetext{
${ }^{3}$ The data from Psacharopoulos [1994] and Barro and Lee [1993]. The countries are Austria Australia, Canada, France, Germany, Italy, Japan, Netherlands, Sweden, Switzerland, the U.K., and the U.S..
} 


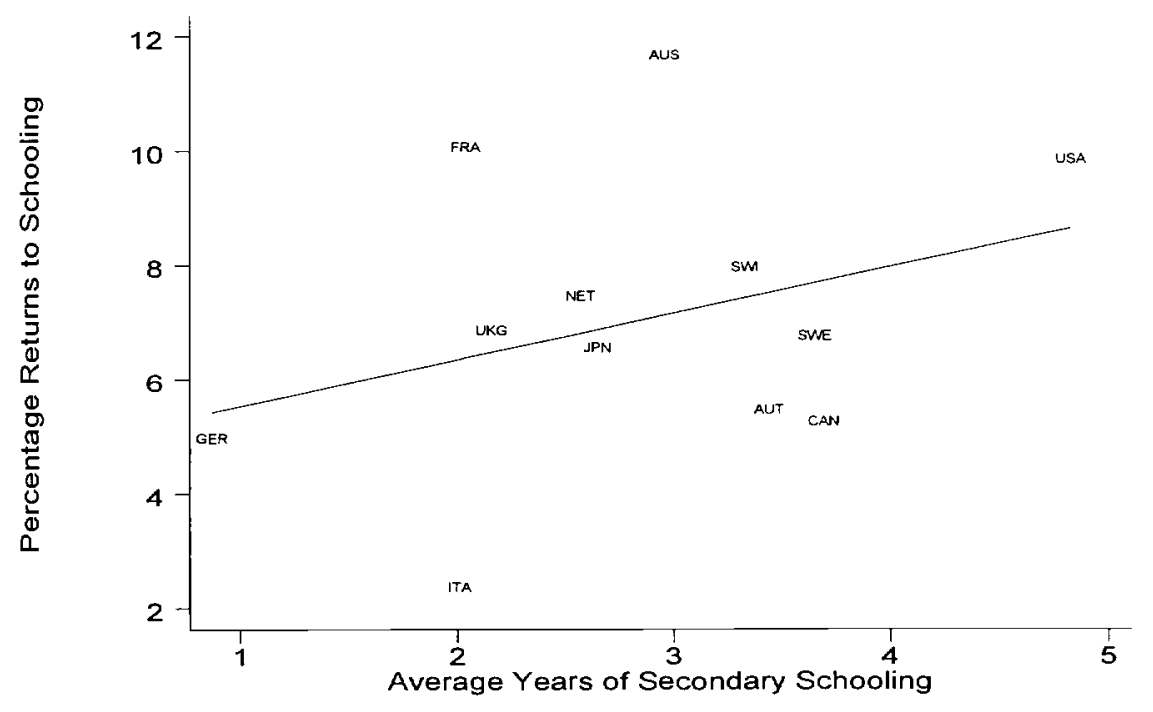

Figure 4: Returns to schooling and average schooling for advanced economies.

negative relationship. Comparing other measures of returns to skills such as overall wage inequality, the pattern, if anything, points to higher skill premia in the more skillabundant U. S. than in Europe. For example, in 1984, the log difference of the 90th and 10th deciles of the hourly wage distribution was 1.40 in the U.S., 1.16 in Britain, 1.23 in France, 1.01 in the Netherlands, 0.88 in Germany, 1.01 in Sweden and 1.04 in Japan (Freeman and Katz [1995], Table 2). In the context of my model, this pattern arises because the skill abundant U.S. develops more skilled-biased technologies than European countries. ${ }^{4}$

The most original results of this paper concern the impact of an increase in the volume of international trade on the patterns of skill premia. Standard trade models imply that international trade should increase skill premia in industrialized countries and reduce it in LDCs. But, during the recent period of trade opening, wage inequality appears to have increased in the U.S. and the LDCs, but not in Continetal Europe. ${ }^{5}$ I show that this pattern may arise because trade affects American and European technologies

\footnotetext{
${ }^{4}$ An alternative explanation for this pattern is institutional wage compression in Europe. I discuss this explanation in the concluding section, and argue that instead demand for skilled workers may be lower in Europe.

${ }^{5}$ See the evidence in Hanson and Harrison [1994] and Robbins [1995] for changes in inequality in the LDCs and see, for example, the papers in the Freeman and Katz [1995] volume.
} 
differentially.

The key to my analysis is that international trade affects the direction of technical change. Trade increases the relative price of skill intensive goods in the U.S., making skill-complementary innovations more profitable, and inducing skill-biased technical change. ${ }^{6}$ Skill-biased change contributes to the rise in inequality in the U.S. coming from standard trade reasons. It also implies that since the LDCs use U.S. technologies, trade may increase, rather than decrease, wage inequality in the LDCs.

This theory therefore avoids two of the major criticisms levelled against explanations that view trade as the major cause of the rise in U.S. wage inequality. The first is that given reasonable estimates of the relevant elasticities, the volume of trade is not sufficient to explain the increase inequality (e.g. Krugman [1995]). The second criticism is that demand for skills appears to have also increased in the LDCs, contrary to the prediction of a standard trade model. Since in this theory trade induces skill-biased technical change, standard calculations would underestimate the impact of trade. With sufficiently pronounced skill-biased change, demand for skills and inequality can also increase in the LDCs. The third major argument against trade is the lack of a significant increase in the prices of skill-intensive goods in the U.S., the main channel through which trade would affect the U.S. labor market (e.g. Lawrence and Slaughter [1994]). I will show that this argument also does not apply in my model because relative prices have to return to their original (pre-trade) level in the U.S. in order to equilibrate incentives to develop different technologies.

The argument so far explains how trade can have a significant effect on the U.S. labor market, while also increasing demand for skills in the LDCs. A puzzling feature of the developments in the patterns of inequality over the past twenty five years has been the stability of returns to schooling and wage inequality in many European economies, in the face of sharply increasing inequality in the U.S.. Surprisingly, this model predicts that increased trade may reduce demand for skills, and hence skill premia in Europe.

\footnotetext{
${ }^{6}$ This argument is closely related to a point informally raised by Wood [1994]. Wood argues that trade with the LDCs led to defensive innovations in the labor-intensive sectors of more developed countries, and these defensive innovations reduced the demand for unskilled labor. Although related in spirit, the two arguments are quite different. In my theory, the increase in the relative price of skilled goods encourages the development of technologies complementary to skilled workers. It is also not clear in Wood's argument why trade should induce defensive innovations, and why these innovations should reduce the demand for skills. For example, if machines complement labor, innovations in the unskilled sector would increase the demand for unskilled labor.
} 
Recall that Europe starts out with fewer skilled workers than the U.S. and with a greater relative price of skill-intensive goods. Trade between the U.S., Europe, and the LDCs, at a given set of technologies, would increase the relative price of skill-intensive goods in Europe, increasing the demand for skills. But U.S. skill-biased technical change induced by trade increases the productivity of skilled workers in the U.S. and the LDCs, so the world economy after trade may have a substantially larger supply of skill-intensive goods and relative prices of skilled goods quite close to those in the U.S. before trade, which were below those in Europe. Demand for skills in Europe can therefore fall as a result of trade opening.

The related literature includes models of the increase in inequality in the U.S., such as Acemoglu [1999], Aghion, Howitt and Violante [1999], Caselli [1999], Galor and Tsiddon [1997], Galor and Maov [1998], Greenwood and Yorkuoglu [1997], Krusell, Ohanian, Rios-Rull and Violante [1997]. Acemoglu [1998] is most closely related. In that paper, I use a similar model of directed technical change to show that the increase in the number of college graduates during the $1960 \mathrm{~s}$ and $1970 \mathrm{~s}$ in the U.S. can explain both the fall of the college premium during the 1970 s and its sharp rise during the 1980s. Here, I extend that model to derive the differential implications across countries and over time, and offer a detailed analysis of the impact of trade on technology and inequality. Previous studies, including among others Ahmad [1965], Kennedy [1964] and Samuelson [1970], Hayami and Ruttan [1970], and David [1975], discuss induced innovations, which is closely related to the concept of directed technical change. But these studies do not feature the market size effect - the fact that an increase in the number of skilled workers increases the size of the market for skill-complementary technologies. The market size effect is central to the results of this paper, especially to those of Section II. Finally, previous contributions that emphasize the importance of trade on inequality include Wood [1994] and Leamer [1995], though they do not model or emphasize the impact of trade on the direction of technical change.

The plan of the paper is as follows. In the next section, I show that in a natural model of endogenous technical change where skill- and labor-complementary technologies can be developed at different rates, there is a strong market size effect. As a result, in a skill-abundant economy, technologies used by skilled workers may be so advanced that there could be an increasing relation between the supply of skills and skill premia. This model can explain the patterns depicted in Figure 1, 2 and 4. In Section III, I develop 
the argument that trade opening can cause skill-biased technical change in the U.S. and labor-biased technical change in Europe. Section IV concludes.

\section{The Basic Model}

\section{A. Preferences}

Consider a world economy consisting of the U.S., and a group of Less Developed Countries (the South). There are two differences between these countries: first, the U.S. is technologically more advanced, and second, it has a higher fraction of skilled workers than the LDCs. ${ }^{7} H$ denotes skilled workers and $L$ denotes unskilled workers, and I assume $H^{U} / L^{U}>H^{S_{j}} / L^{S_{j}}$ for $j=1, . ., J$, where $U$ denotes the U.S. and $S_{j}$ denotes $j^{\text {th }}$ Southern country. For now, I allow no international trade, and in this subsection, I drop country superscripts.

All consumers in all countries have identical preferences:

$$
U(t) \equiv \int_{t}^{\infty} \exp (-r(\tau-t)) c_{k}(\tau) d \tau
$$

where $c(\tau)$ is consumption at time $\tau$ and $r$ is the discount rate, and due to linear utility, it is also the interest rate. I will drop the time argument when this causes no confusion.

The consumption good is produced from two complementary intermediate goods, one using skilled and the other unskilled labor. The market for intermediate goods is competitive. I denote the total output of these intermediate goods by $Y_{l}$ and $Y_{h}$. The aggregate production of the consumption good is:

$$
Y=\left[Y_{l}^{\rho}+\gamma Y_{h}^{\rho}\right]^{1 / \rho}
$$

where $\rho \leq 1$, and the elasticity of substitution is $1 /(1-\rho)$. I denote the prices of the two intermediate goods by $p_{l}$ and $p_{h}$. The relative price of the skill-intensive good is:

$$
p \equiv \frac{p_{h}}{p_{l}}=\gamma\left(\frac{Y_{l}}{Y_{h}}\right)^{1-\rho}
$$

I use the final good as the numeraire so that $\left[p_{l}^{\frac{-\rho}{1-\rho}}+p_{h}^{\frac{-\rho}{1-\rho}}\right]^{-\frac{1-\rho}{\rho}}=1$. The labor market is also assumed to be competitive.

\footnotetext{
${ }^{7}$ The important feature is not that these countries are less developed, but that they are technological followers, using U.S. technologies.
} 


\section{B. Technology}

There are two technologies, one complementing skilled labor in the production of the skill-intensive good, the other complementing unskilled labor in the production of the labor-intensive good.

The output of the two goods in country $c$ are:

$$
Y_{l}^{c}=\int_{0}^{1} \widehat{q}_{l}^{c}(i) x_{l}(i)^{1-\beta} d i \cdot\left(L^{c}\right)^{\beta} \text { and } Y_{h}^{c}=\int_{0}^{1} \widehat{q}_{h}^{c}(i) x_{s}(i)^{1-\beta} \cdot\left(H^{c}\right)^{\beta},
$$

where $\widehat{q}_{s}^{c}(i)$, for $s=l, h$, is the quality of machine $i$ used in the production of good $s$ in country $c$, and $x_{s}^{c}(i)$ is the quantity of this machine used in production. So there is a range (a continuum 1) of different types of machines used by unskilled workers and a different set used by skilled workers. This setup is similar to that in Acemoglu [1998] as it allows skilled and unskilled workers to use different technologies. Technological progress will take the form of improvements in machine qualities. Having a range of machines, rather than only one for each skill type, simplifies the analysis by making technical progress deterministic and continuous.

Producers use the machines developed locally or adopt machines developed in another country, $c^{\prime}$. But in this latter case, because these machines are not "appropriate" to their needs, their productivity will be lower than producers in the country of origin by a factor $\theta \leq 1$. There are many possible reasons for this inappropriateness of technologies. Countries require crops suitable for their own climate, vaccines that deal with the prevalent diseases in their region, and technologies that exploit their existing knowhow. So technologies developed in the U.S. may be partly "inappropriate" to different environments, and hence less productive when used in other countries. ${ }^{8}$

Since producers will adopt the most productive machines, we have

$$
\widehat{q}_{s}^{c}(i)=\max \left\langle q_{s}^{c}(i), \theta \max _{c^{\prime}}\left\{q_{s}^{c^{\prime}}(i)\right\}\right\rangle,
$$

where $q_{s}^{c}$ is the productivity of the most advanced machine developed in country $c$.

The U.S. is technologically more advanced than the South. In particular, $\theta q_{s}^{U}(i)>$ $q_{s}^{S_{j}}(i)$ for $s=l, h$ and all $j$ and $i$. This implies that it is profitable for the LDCs to import their machines from the U.S., so $\widehat{q}_{s}^{c}(i)=\theta q_{s}^{U}(i)$. I also assume that there are no

\footnotetext{
${ }^{8}$ Basu and Weil [1998] and Acemoglu and Zilibotti [1998] emphasize the importance of "appropriateness" of technologies in the context of economic development (see also Atkinson and Stiglitz [1975], Salter [1966], Stewart [1974]).
} 
intellectual property rights between the U.S. and less developed economies, so that if an LDC uses machines developed in the U.S., it does not pay patent fees to the innovators of the machine. Instead, in each LDC, an imitator can patent technologies developed in the North at cost $\varepsilon$, and become the monopolist supplier of these machines. ${ }^{9}$ Finally, I assume that an R\&D firm can only develop the machines that are appropriate in its own country, so that firms in the South cannot perform R\&D for machines that are being developed in the U.S..

I denote the price of machine $i$ for skill type $s$ in country $c$ by $\chi_{s}^{c}(i)$. Equation (4) implies that the demand for machine $\widehat{q}_{s}^{c}(i)$ is $x_{s}^{c}(i)=\left[(1-\beta) p_{s}^{c} \widehat{q}_{s}^{c}(i)\left(N_{s}^{c}\right)^{\beta} / \chi_{s}^{c}(i)\right]^{1 / \beta}$ where $N_{h}^{c} \equiv H^{c}$ and $N_{l}^{c} \equiv L^{c}$. Product prices, $p_{s}^{c}$, are indexed by $c$ as they vary across countries in the absence of international trade.

The R\&D process is modeled as in Aghion and Howitt [1992] and Grossman and Helpman [1991]: an innovation based on a machine of quality $q$ creates a new vintage with quality $\lambda q$ where $\lambda>1$. The inventor of a new machine obtains a patent, enforced only in the U.S.. I assume $\lambda<(1-\beta)^{-(1-\beta) / \beta}$, which ensures that R\&D firms in the U.S. will set a limit price making final good firms indifferent between buying the two newest vintages. The marginal cost of producing a machine of quality $q$ increases linearly in $q$ and I normalize it to $(1-\beta)(\lambda-1)^{-1} q$. This implies that the price of a machine of quality $q$ in the U.S. is $\chi^{U}=(1-\beta) q$. Similarly, the imitating monopolist in each LDC will also maximize profits by setting the same limit price, so $\chi^{c}=(1-\beta) q$ for all $c$. Substituting this price into machine demands, we obtain the quantity of machines used in production as: $x_{s}^{c}(i)=\left[p_{s}^{c} \widehat{q}_{s}^{c}(i)\left(N_{s}^{c}\right)^{\beta}\right]^{1 / \beta}$ in country $c$. Using this expression, output in sector $s$ is:

$$
Y_{s}^{c}=\left(p_{s}^{c}\right)^{(1-\beta) / \beta} \widehat{Q}_{s}^{c} N_{s}^{c}
$$

where $\widehat{Q}_{s}^{c} \equiv \int_{0}^{1} \widehat{q}_{s}^{c}(i) d i$ is a measure of the aggregate productivity of machines used in sector $s$ in country $c$. The wage, the marginal product of labor, is therefore: $w_{s}^{c}=$ $\beta\left(p_{s}^{c}\right)^{1 / \beta} \widehat{Q}_{s}^{c}$. Since $\widehat{q}_{s}^{c}(i)=\theta q_{s}^{U}(i)$, we have that $\widehat{Q}_{s}^{c}=\theta Q_{s}^{U}$, so $\widehat{Q}_{H}^{c} / \widehat{Q}_{L}^{c}=Q_{H}^{U} / Q_{L}^{U}$. Hence, denoting $Q_{s}^{U}=Q_{s}$ to simplify notation, the skill premium in country $c$ is:

$$
\omega^{c} \equiv \frac{w_{h}^{c}}{w_{l}^{c}}=\left(p^{c}\right)^{1 / \beta} \frac{Q_{h}}{Q_{l}} .
$$

Skill premia therefore depend on technology and product prices. In two countries with

\footnotetext{
${ }^{9}$ Given Bertrand competition, it is not profitable for any other firm to adopt ("steal") the same patent.
} 
the same technology and with the same product prices, the relative wage should the same. In this section, skill premia will differ between the U.S. and the LDCs because, in the absence of international trade, their product prices differ. Simple algebra using (3), (4) and (6) gives the relative price $p^{c}$ as a function of $H^{c} / L^{c}$ :

$$
p^{c}=\gamma^{\beta \nu}\left(\frac{Q_{h}}{Q_{l}}\right)^{-\beta(1-\rho) \nu}\left(\frac{H^{c}}{L^{c}}\right)^{-\beta(1-\rho) \nu},
$$

where $\nu \equiv(1-(1-\beta) \rho)^{-1}$. An increase in $H^{c} / L^{c}$ therefore increases the relative supply of skill-intensive goods and depresses $p^{c}$. Now, combining this with (7), we obtain:

$$
\omega^{c}=\gamma^{\nu}\left(\frac{Q_{h}}{Q_{l}}\right)^{\beta \rho \nu}\left(\frac{H^{c}}{L^{c}}\right)^{-(1-\rho) \nu} .
$$

This is the crucial equation of the paper. For a given state of technological knowhow (skill bias) as captued by $Q_{h} / Q_{l}$, the skill premium $\omega^{c}$ is decreasing in the supply of skills. Therefore, across countries sharing the same technology, there will be a decreasing relation between the relative supply of skills and the skill premium, as suggested by Figure 2 .

\section{Directed Technical Change in the U.S.}

I now analyze the forces that determine the equilibrium skill bias of technologies. Recall that for now, new technologies are developed only in the U.S..

The value of owning the leading vintage of machine $i$ in sector $s$ is:

$$
r V_{s}(i)=\pi_{s}(i)-z_{s}(i) V_{s}(i)+\dot{V}_{s}(i)
$$

where $z_{s}(i)$ is the flow rate of a new invention, and $\pi_{s}(i)=\beta x_{s}^{U}(i) q_{s}(i) /(1-\beta)$ is the flow profit from selling a machine of vintage $q_{s}(i)$. Notice that only $H^{U}$ and $L^{U}$ feature in $x_{s}^{U}(i)$, and hence in $\pi_{s}(i)$, because innovators can only sell their technologies in the U.S. market. Although LDC firms use U.S. technologies, they do not pay patent fees or royalties to U.S. firms. There will also be no R\&D in the LDCs since LDC firms prefer to use U.S. technologies.

Finally, free-entry into R\&D activities implies that an additional dollar spent for research must yield a return equal to cost. One unit of the final good spent in $R \& D$ for a machine of quality $q$ leads to a discovery of a new machine at the flow rate conveniently 
normalized to $(1-\beta) /(\beta q)$. Since the flow rate of invention is decreasing in $q$, more resources need to be spent to discover a higher quality machine. Free-entry then implies

$$
V_{s}(i)=\frac{\beta}{1-\beta} q_{s}(i)
$$

An equilibrium requires that firms choose the profit maximizing technology and rent the profit maximizing amounts of all inputs; innovators follow the profit maximizing pricing policy; product, intermediate good and labor markets clear; and there is no opportunity for any research firm to enter (or exit) and increase its profits. Equations (5), (8), (9), (10) and (11) ensure these conditions.

I start with the balanced growth path (BGP) along which $\dot{V}=0$. Imposing this condition, equations (10) and (11) imply that in BGP:

$$
\left(p_{s}\right)^{1 / \beta} N_{s}=B\left[r+z_{s}(i)\right]
$$

for $s=l, h$. This equation states that innovation effort in sector $s$ will be higher when profits from technology sales, the left-hand side, are higher. The profits will be higher in turn when the prices of the goods they produce are higher and/or when more workers use this technology. It also immediately follows from (12) that $z_{s}(i)=z_{s}$ for all $i$. In other words, the BGP levels of innovation for all skill-intensive (labor-intensive) technologies are the same, so we only have to determine two variables, $z_{l}$ and $z_{h}$.

Combining (12) for $s=l$ and $s=h$, we see that $z_{h} / z_{l}$, relative research effort at skill-complementary technologies, is increasing in $p^{U}\left(H^{U} / L^{U}\right)^{\beta}$. It is only the relative supply in the U.S. that matters because, in the absence of international property rights, U.S. workers constitute the sole market for new technologies.

We can now see that the direction of technical change is determined by two factors (see Acemoglu [1998]):

1. The price effect: technologies producing more expensive goods will be upgraded faster. Since goods using the scarce factor will command a higher price (see (8) above), this effect implies that there will be more innovation directed at the scarce factor.

2. The market size effect: a larger clientele for the technology leads to more innovation. Since the clientele for the technology is effectively the workers who use it, the market size effect encourages innovation for the more abundant factor. 
Equilibrium bias in technical change is determined by these two opposing forces. A greater supply of skilled workers, via the price effect, induces the development of more labor-complementary technologies. When there are more skilled workers, the size of the market for skill-complementary technologies is also larger, and this encourages further skil-biased technical change. We will see below that for $\rho \in(0,1]$, this market size effect is more powerful.

More formally, for BGP, we need $q_{h} / q_{l}$ to be constant, therefore $z_{l}=z_{h}$. Equation (12) then implies that along the BGP:

$$
p^{U}=\left(\frac{H^{U}}{L^{U}}\right)^{-\beta} .
$$

Intuitively, BGP requires both sectors to grow at the same rate, hence $z_{l}=z_{h}$. So the demand for skill-complementary technologies relative to labor-complementary machines should be independent of $H^{U} / L^{U}$, and the price and market size effects should exactly balance out, which is ensured by (13). Equations (8) and (13) imply that the BGP relative productivity of skilled workers satisfies:

$$
\frac{Q_{h}}{Q_{l}}=\gamma^{\frac{1}{1-\rho}}\left(\frac{H^{U}}{L^{U}}\right)^{\frac{\beta \rho}{1-\rho}} .
$$

$Q_{h} / Q_{l}$, the average quality of skill-complementary machines relative to labor-complementary machines, is the measure of equilibrium skill bias.

First, consider the case of $\rho>0$ so that skill and labor-intensive goods are relatively close substitutes. Then, of the two influences on the direction of technical change, the market size effect is stronger. Since profits to innovation are proportional to market size, they are proportional to the number of workers using the technology. Therefore, when $H^{U} / L^{U}$ increases, innovation and $\mathrm{R} \& \mathrm{D}$ in the skill-intensive sector become more profitable, inducing $Q_{h} / Q_{l}$ to increase. This case is of interest, as it implies that an inrease in the relative supply of skilled workers in the U.S. will lead to a higher demand for skilled workers as suggested by Figure 1.

In contrast, when $\rho<0$, the price effect is more powerful. An increase in $H^{U} / L^{U}$ leads to a large reduction in $p^{U}$, making innovation and $\mathrm{R} \& \mathrm{D}$ in the skill-intensive sector relatively less profitable. This causes a reduction in $Q_{h} / Q_{l}$. Although it is plausible for the price effect to dominate in many cases, ${ }^{10}$ the market size effect is likely to dominate

\footnotetext{
${ }^{10}$ For example, Hayami and Ruttan $[1970]$ discuss the different paths of agricultural development in
} 
in the case of skilled and unskilled workers. ${ }^{11}$ So in the rest of the analysis I take $\rho$ to be positive.

Returning to the formal analysis, the BGP research effort level can now be determined from (12), (13) and (14) by imposing $z_{l}=z_{h}=z$, which gives:

$$
r+z^{c}=\left[\gamma\left(H^{U}\right)^{\frac{\beta \rho}{1-\rho}}+\left(L^{U}\right)^{\frac{\beta \rho}{1-\rho}}\right]^{\frac{1-\rho}{\rho \beta}} .
$$

Finally, using the analysis so far and (9), we have:

Proposition 1: Suppose there is no international trade and no intellectual property rights. Then, there is a unique balanced growth path (BGP) where in all countries, both sectors and total output grow at the rate $(\lambda-1) z$ with $z$ given by (15). Along the BGP, $Q_{h} / Q_{l}$ is given by (14) and the skill premiumin the U.S. is:

$$
\omega^{U}=\gamma^{\frac{1}{1-\rho}}\left(\frac{H^{U}}{L^{U}}\right)^{\eta}
$$

where $\eta \equiv \beta \rho^{2} /(1-\rho)-(1-\beta \rho)$. The skill premium in country $S_{j}$ in the South is:

$$
\omega^{S_{j}}=\gamma^{\frac{1}{1-\rho}}\left(\frac{H^{U}}{L^{U}}\right)^{\frac{\rho^{2} \rho^{2} \nu}{1-\rho}}\left(\frac{H^{S_{j}}}{L^{S_{j}}}\right)^{-(1-\rho) \nu} .
$$

Notice that in this economy there are no transitory dynamics. Since preferences and research technology are linear, $Q_{h} / Q_{l}$ immediately jumps to its BGP value. ${ }^{12}$

This proposition summarizes the crucial results of our basic analysis. In the unique BGP there is a 1-to-1 relation between the relative supply of skilled workers in the U.S.

the United States and Japan. The scarcity of land in Japan relative to the United States appears to have induced a faster rate of innovation and adoption of fertilizers, increasing output per acre.

${ }^{11}$ The high degree of substitution between skilled and unskilled workers suggested by the increased share of college educated workers within almost all narrowly defined industries, for example, suggests a high elasticity of substitution (e.g. Autor, Katz and Krueger [1998]). Moreover, when $\rho<0, \frac{d \omega}{d Q_{h} / Q_{l}}<0$, which runs counter to the presumption that when the skill-complementary technology improves, the skill-premium increases. Finally, and most importantly, the short-run (constant technology) elasticity of substitution between high and low education workers in this model is $\sigma=(1-(1-\beta) \rho) /(1-\rho)$. In the data, most estimates are greater than 1 (see Freeman [1986]), which implies $1 / \sigma=(1-\rho) /(1-(1-\beta) \rho)<$ 1 , and therefore $\rho>0$. Since a large part of the substitution between skilled and unskilled workers is within industries, $\rho$ should not be interpreted as the elasticity of substitution between different goods.

${ }^{12}$ CRRA rather than linear preferences would make adjustment to BGP gradual, without affecting the rest of the results. 
and their relative wage. This relation can be either increasing or decreasing. If technology were exogenous in this economy, i.e. $Q_{h} / Q_{l}$ were constant or changing exogenously, the skill premium would be a decreasing function of $H / L$. When technology is endogenous, however, a greater $H / L$ encourages more R\&D activity in the skill-complementary technologies. If this directed technology effect, $\beta \rho /(1-\rho)$ from $(14)$, is large enough, $\eta$ will be positive, and the long-run relative demand curve for skills will be upward sloping as $\mathrm{ET}_{2}$ in Figure 3. In this case, the higher supply of skilled workers in the U.S. may lead to increasing returns to skills, in line with the developments in the U.S. labor market.

Equation (17), on the other hand, shows that the cross-country relation between the supply of skills and skill premia will be decreasing as the data in Figure 2 suggest. In particular, a higher $H^{S_{j}} / L^{S_{j}}$ leads to a lower skill premium, because among LDCs, changes in skill supply move a country along the constant technology relative demand curve for skills, CT, in Figure 3. Interestingly, this proposition implies that an increase in the U.S. supply of skilled workers, $H^{U} / L^{U}$, will lead to an increase in the skill premium in LDCs.

It is also interesting to observe that when $\rho<0$, we always have $\eta<0$. But even in this case the over time behavior of the economy will correspond to a more elastic (less negatively sloped) curve, such as $\mathrm{ET}_{1}$ in Figure 3, than the constant technology CT curve describing cross-country behavior. This is because as (14) shows, an increase $H / L$ reduces $Q_{h} / Q_{l}$, but in this case, (9) implies that the skill premium is decreasing in $Q_{h} / Q_{l}$.

Finally, it is useful to observe that if $\eta$ is positive, a possible explanation for the increase in the demand for skills in the U.S. and the LDCs is the increase in the supply of skilled workers in the U.S. labor market during the 1960s and 1970s. As argued in Acemoglu [1998], this large increase in the supply of skills could have caused skill-biased technical change, increasing wage inequality in the U.S. and in countries using U.S. technology. In the next section, I propose a complementary mechanism for the increase in wage inequality in the U.S. and the LDCs, trade opening, which may also lead to a decrease in wage inequality in Europe.

\section{Intellectual Property Rights in the South}

The analysis so far assumed no property rights in the South. It is straightforward to analyze the other extreme where there is full enforcement of property rights in the 
South. Define $H^{W} \equiv H^{U}+\theta H^{S}$ as the market for skill complementary machines, where $H^{S}$ is the total number of skilled workers in the South. $H^{S}$ is multiplied by $\theta$ because U.S. machines are less productive, by a factor of $\theta$, when used in the LDCs, so LDCs use fewer machines per worker. Similarly, the market for labor complementary machines is $L^{W} \equiv L^{U}+\theta L^{S}$. The only difference from our analysis so far is that equation (14) is replaced by

$$
\frac{Q_{h}}{Q_{l}}=\gamma^{\frac{1}{1-\rho}}\left(\frac{H^{W}}{L^{W}}\right)^{\frac{\beta \rho}{1-\rho}}
$$

and equation (16) and (17) are replaced by

$$
\omega^{c}=\gamma^{\frac{1}{1-\rho}}\left(\frac{H^{W}}{L^{W}}\right)^{\frac{\beta^{2} \rho^{2} \nu}{1-\rho}}\left(\frac{H^{c}}{L^{c}}\right)^{-(1-\rho) \nu},
$$

for $c=U$ or $S_{j}$.

In this case, the relation between the relative supply of skills and skill premia across countries continues to be decreasing, consistent with Figure 2. However, the link between the U.S. supply of skills and the skill bias of the U.S. is weakened. An increase in the U.S. supply of skills, $H^{U} / L^{U}$, will have only a small effect on $H^{W} / L^{W}$, and hence on $Q_{h} / Q_{l}$, though the sign of the relation is unchanged. So as long as $\eta>0$, an increase in $H^{U} / L^{U}$ will continue to induce skill-biased technical change, but this effect is likely to be small. An increase in the relative supply of skills in the world, on the other hand, will induce skill-biased technical change in the U.S.. Since over the period 1950-1996, the world supply of skills was also increasing rapidly, this version of the model is still consistent with Figure 1.

\section{E. The U.S. versus Europe}

To address the contrast between the U.S. and Europe, I now introduce another developed country, "Europe", denoted by superscript E. In contrast to the LDCs, Europe is relatively technologically advanced. In particular, I assume $q_{s}^{U}(i)>q_{s}^{E}(i)>$ $\theta q_{s}^{U}(i)$ for $s=l, h$ and all $i .{ }^{13}$ This implies that the U.S. is more advanced than Europe, but Europe is sufficiently developed that European firms will prefer to use technologies designed for their own needs rather than the U.S. ones. So there will be research in

\footnotetext{
${ }^{13}$ The results generalize to the case of many "Europan" countries and to the case where Europe develops only a fraction of the machines, using U.S. technology in the rest.
} 
Europe, improving European technologies. Since the U.S. is more advanced than Europe, the LDCs will continue to use U.S. technologies.

The equations that describe technology choice in the U.S. now apply in Europe as well. Specifically, the equivalent of (14) now holds for Europe:

$$
\frac{Q_{h}^{E}}{Q_{l}^{E}}=\gamma^{\frac{1}{1-\rho}}\left(\frac{H^{E}}{L^{E}}\right)^{\frac{\beta \rho}{1-\rho}}
$$

It is therefore clear that differences in the relative supply of skills between the U.S. and Europe will cause different degrees of skill bias in the two economies. As long as $\rho$ is positive, equations (14) and (18) imply that the U.S. will develop more skillbiased technologies than Europe. Interestingly, if this induced technology effect is strong enough, that is, if $\eta$ is positive, the U.S. may have higher returns to skills despite its greater supply of skills. In general, therefore, we expect no definite relation between the relative supplies of skills and skill premia among economies developing their own technologies. So, the pattern discussed in the introduction whereby inequality is higher in the U.S. is certainly possible.

To fully characterize the equilibrium in the world economy consisting of the U.S., Europe, and the LDCs, first recall that because U.S. technologies are more advanced than the European ones, LDCs will use U.S. technologies, so $\widehat{q}_{s}^{S_{j}}(i)=\theta q_{s}^{U}(i)$ for all $S_{j}$. Additionally, I impose:

Assumption 1: $\left[\gamma\left(H^{U}\right)^{\frac{\beta \rho}{1-\rho}}+\left(L^{U}\right)^{\frac{\beta \rho}{1-\rho}}\right]=\left[\gamma\left(H^{E}\right)^{\frac{\beta \rho}{1-\rho}}+\left(L^{E}\right)^{\frac{\beta \rho}{1-\rho}}\right]$.

The role of Assumption 1 is to ensure that the U.S. and Europe grow at the same rate. Otherwise the general argument here continues to apply, but because either European or U.S. technologies improve faster, both economies will eventually use the same technologies. The following proposition is now immediate:

Proposition 2: Suppose that there is no international trade, no intellectual property rights and Assumption 1 holds. Then, there is a unique BGP in both sectors and total output in all countries grow at the rate $(\lambda-1) z$ with $z$ given by (15). Along the BGP, $Q_{h}^{U} / Q_{l}^{U}$ is given by (14), $Q_{h}^{E} / Q_{l}^{E}$ is given by (18), the skill premium in the U.S. is given by (16), and the skill premium in Europe is:

$$
\omega^{E}=\gamma^{\frac{1}{1-\rho}}\left(\frac{H^{E}}{L^{E}}\right)^{\eta}
$$


where $\eta \equiv \beta \rho^{2} /(1-\rho)-(1-\beta \rho)$. The skill premium in country $S_{j}$ in the South is given by (17).

The important conclusion is that skill premia between the U.S. and Europe differ not only because of differences in product prices, but also because the two economies are using different technologies. As a result, if $\eta>0$, then the greater supply of skills in the U.S. induces the development of sufficiently skill-biased technologies and increases the U.S. skill premium above that in Europe, that is $\omega^{U}>\omega^{E}$. This is despite the fact that $p^{E}>p^{U}$, so if the two economies had used the same technologies, (7) would have implied $\omega^{U}<\omega^{E}$. Also if $\eta>0$, increases in the supply of skills in the U.S. raise skill premia there. The relation between the supply of skills and the skill premium among the LDCs continues to be decreasing. So in the case with $\eta>0$, the model is consistent with the range patterns outlined in the introduction.

\section{Trade Opening and Changes in Skill Premia}

I now consider the impact of an increase in the volume of trade on patterns of skill premia. Once again, I start with an economy that consists of the U.S. and the LDCs, and then add Europe. In all of these cases, I compare the two extreme cases of no international trade and free international trade. Although a gradual opening is certainly more realistic, the sudden opening illustrates the main forces at work and is much simpler. I also assume that intellectual property rights continue not to be enforced in the South. Finally, it is useful to observe at this point that despite the emphasis on the case with $\eta>0$ in the previous section, the results in this section do not depend on the sign of $\eta$, but simply on $\rho>0$, which is a much weaker requirement.

\section{A. Trade and Skill-Biased Technical Change}

Consider the world economy consisting of the U.S. and the LDCs in BGP as described in Proposition 1. Now open the world economy to free trade. This will immediately equalize the prices of intermediate goods $Y_{l}$ and $Y_{h}$, in all countries, so the relative price of skill-intensive goods in all countries after trade is $p^{T}$.

Equation (7) links the skill premium to technology and prices. In the previous section, skill premia differed across the LDCs and the U.S. because goods prices differed. Trade 
equalizes prices at $p^{T}$, and hence skill premia are also equalized, so $\omega^{U}=\omega^{S_{j}}=\omega$. This result is independent of whether there is property rights enforcement in the South. Notice, however, that this observation does not guarantee factor price equalizations since U.S. technologies are less productive when used in the LDCs. So U.S. workers will be earning higher wages than LDC workers.

Next, consider the determination of the equilibrium skill bias. To start, I assume that there are no property rights in the LDCs irrespective of whether there is international trade. This means that the market sizes for new technologies are not affected by trade opening, and therefore equation (13) has to hold, so $p^{T}=\left(H^{U} / L^{U}\right)^{-\beta}=p^{U}$. This has a striking implication: trade will not affect the relative prices of skill intensive goods in the U.S. because of its effect on technical change! Therefore, the world relative price of skill-intensive goods after trade, $p^{T}$, must equal $p^{U}$, the U.S. relative price of skillintensive goods before trade. Since $p^{S_{j}}>p^{U}$, this also implies that trade opening will reduce the relative price of skilled goods in the LDCs.

To fully characterize the equilibrium, we only need to determine equilibrium skill bias, $Q_{h} / Q_{l}$, after trade. Recall that prices are determined by the world supply of skill-intensive and labor-intensive goods. Therefore, equation (3), instead of (8) in the previous section, gives the relative price of skill-intensive goods as:

$$
p^{T}=\gamma^{\beta \nu}\left(\frac{Q_{h}}{Q_{l}}\right)^{-\beta(1-\rho) \nu}\left(\frac{H^{W}}{L^{W}}\right)^{-\beta(1-\rho) \nu},
$$

where $H^{W}$ and $L^{W}$ are, as before, the effective world supplies.

Combining this with equation (13), we obtain the equilibrium skill bias after trade:

$$
\left(\frac{Q_{h}}{Q_{l}}\right)^{T}=\gamma^{\frac{1}{1-\rho}} \zeta^{-1}\left(\frac{H^{U}}{L^{U}}\right)^{\frac{\beta \rho}{1-\rho}}
$$

where $\zeta$ is defined as $H^{W} / L^{W} \equiv \zeta\left(H^{U} / L^{U}\right) . \zeta$ is naturally less than 1 , hence:

$$
\left(\frac{Q_{h}}{Q_{l}}\right)^{T}>\left(\frac{Q_{h}}{Q_{l}}\right)^{N T}
$$

where $N T$ denotes no trade.

Equations (20) and (21) are another important result of our analysis. They imply that trade opening induces skill-biased technical change in the U.S.. To understand this, recall that the direction of technical change is determined by a market size effect and a 
price effect. Since property rights continue not to be enforced in the South, the market size effect is unchanged. Trade, however, increases the price of skill-intensive goods in the U.S. because the LDCs are more abundant in unskilled workers. The increased price of skilled goods makes skill-complementary innovations more profitable and induces skillbiased technical change. This effect is so strong that the relative prices of skilled goods return to their initial level before trade opening. ${ }^{14}$

It is now possible to characterize the response of skill premia in different countries to trade opening. Once again using supscripts $T$ and $N T$ to denote pre and post-trade values, we have

$$
\left(\omega^{U}\right)^{T}=\left(\omega^{S}\right)^{T}=\zeta^{-\beta \rho \nu}\left(\omega^{U}\right)^{N T}
$$

Since $\zeta<1$, this implies that skill premia in the U.S. necessarily increase (still focusing on the case $\rho>0$ ). In the South, skill premia converge to the new U.S. skill premia. Whether they increase overall or not depends on their pre-trade values. In particular, recalling equation (17), we see that wage inequality will increase if

$$
\frac{H^{S_{j}}}{L^{S_{j}}}>\zeta^{\beta \rho /(1-\rho)}\left(\frac{H^{U}}{L^{U}}\right) .
$$

LDCs for which this inequality holds will experience an increase in inequality, while the rest will experience a decline.

The analysis in this section therefore leads to a number of conclusions significantly different from the standard trade models. First, directed technical change implies that trade with the LDCs induces skill-biased technical change. The impact of trade on labor markets may therefore be much larger than predicted by standard trade models. Second, there is a force counteracting the decline in inequality in the LDCs implied by trade: these economies use U.S. technologies, which are becoming more skill-biased. Third, and quite strikingly, trade leaves the relative price of skill-intensive goods in the U.S. unchanged! Changes in relative prices are the usual intervening mechanism in trade models. So in evaluating the impact of trade on labor markets, previous work has looked for evidence of an increase in the relative prices of skill intensive goods (e.g., Lawrence and Slaughter [1994], Lawrence [1994], Sachs and Shatz [1995], and Krueger [1997]).

\footnotetext{
${ }^{14}$ Therefore, along the equilibrium path, there is no actual increase in the relative price of the skillintensive good. With transitory dynamics, the relative price of skill-intensive goods would increase first, and then return to its initial level.
} 
In this model, however, we should expect no such changes; the relative price of skillintensive goods in the U.S. is unaffected by trade. More generally, induced skill-biased technical change in the U.S. implies that trade will increase the price of skill-intensive goods by only a limited amount, but will still have a major effect on the U.S. labor market. The inconclusive or paradoxical evidence reported in these papers does not constitute a rejection of trade as the main driving-force-of-rising-inequality view.

\section{B. The Importance of Property Rights}

Exactly the same results would be obtained, if intellectual property rights were enforced fully in the South before trade. Once again, trade does not affect the market sizes for new technologies, so it will induce skill-biased technical change.

Very different results would be obtained, however, if before trade property rights were not enforced in the South, and trade led to the enforcement of these rights. To see this, consider the extreme case of no property rights before trade, and full property rights enforcement after trade. The impact of trade on skill premia in the U.S. and on the direction of technical change is now given by our analysis in Section II by considering an increase in $H / L$ in equation (14). In this case, provided that $\rho>0$, trade will not lead to skill-biased technical change. On the contrary, it will induce the creation of more labor-intensive technologies because with the addition of unskilled workers from the LDCs to the world economy, the market size for these technologies has increased. In fact, if $\eta$ is positive, trade opening can reduce the skill premium in the U.S., which contrasts sharply with standard results from trade theory. I believe, however, that the more relevant case is the one in which trade does not affect the degree of intellectual property right enforcement, and therefore induces skill-biased technical change.

\section{The Impact of Trade on Europe}

I now add Europe to the analysis, and show that trade opening may reduce the demand for skills in Europe. In this subsection, I use the simplest model of trade where U.S., European, and LDC goods are perfect substitutes, which leads to extreme results. In the next subsection, I generalize the framework by introducing some Ricardian elements. Throughout, I simplify the analysis by assuming that Europe is small relative to the rest of the world economy. 
First, consider the world economy before trade. The equilibrium is given by Proposition 2. Notice that at this point, $p^{U}<p^{E}<p^{S_{j}}$ for all $j$, so the relative price of skill-intensive goods is highest in the LDCs, next in Europe, and then in the U.S..

Now suppose the world economy opens to trade, and hypothetically hold technologies fixed. Trade would lead to a new, common, relative price $p^{t}$ as in the previous subsection (I am using lower case superscript to distinguish this hypothetical fixed technology case). It is clear that $p^{S_{j}}>p^{t}>p^{U}$, so the relative price of skill-intensive goods would increase in the U.S. and would fall in the LDCs. The effect on Europe is ambiguous. It depends on the relative sizes of the U.S. and the LDCs, and the distance between Europe and these other countries. Throughout, I assume that without a change in technologies, the prices of skill-intensive goods in Europe will increase, that is $p^{t}>p^{E}$, which is the reasonable case in practice. ${ }^{15}$ Therefore, in the absence of an induced change in technology, the impact of trade would be to increase the demand for skills in Europe. However, we will see that when technical change is endogenous, demand for skills in Europe will fall.

Now consider the world economy with endogenous technology opening to trade. We know from the previous subsection that the relative price of skill-intensive goods, $p^{T}$, will have to adjust to satisfy (13) in the U.S.. This implies that the technology equilibrium condition in Europe, $p=\left(H^{E} / L^{E}\right)^{-\beta}$, will not be satisfied. In fact, we have

$$
p^{T}=p^{U}=\left(H^{U} / L^{U}\right)^{-\beta}<\left(H^{E} / L^{E}\right)^{-\beta}=p^{E} .
$$

Skilled goods are now too cheap, given the number of skilled workers in Europe, for skilled innovations to be profitable. European firms will therefore develop only laborcomplementary technologies, and European skill-complementary technologies will stagnate. As U.S. skill-complementary technologies advance, at some point it will be profitable for European firms to begin using U.S. technologies in the skill-intensive sector. As a result, trade has induced labor-biased technical change in Europe, while causing skill-biased technical change in the U.S..

The behavior of the skill-premium in Europe is simple to characterize. From equation (22), the price of skill-intensive goods in Europe falls after trade opening. Equation

${ }^{15}$ The exact assumption to ensure this is:

$$
\left(\frac{H^{U}}{L^{U}}\right)^{\frac{\beta_{\beta},}{1-\phi}}\left(\frac{H^{U}+\theta H^{S}}{L^{U}+\theta L^{S}}\right)<\left(\frac{H^{E}}{L^{E}}\right)^{\frac{\beta_{0}}{1-\theta^{\prime}}}\left(\frac{H^{E}}{L^{E}}\right) .
$$


(7) implies that at given technologies, $Q_{H}^{E} / Q_{L}^{E}$, the skill premium in Europe, $\omega^{E}$, will fall. Next, since $p^{T}<\left(H^{E} / L^{E}\right)^{-\beta}$, European research firms will invest in developing labor-complementary machines while skill-complementary technologies stagnate. After a while, as U.S. technologies advance enough, European firms will switch to using U.S. technologies. Overall, Europe will definitely end up with a lower skill premium than before trade.

It is useful to reiterate at this point that if $Q_{H}^{U} / Q_{L}^{U}$ remained constant after trade, we would have (by assumption) $p^{t}>p^{E}$, so from (7), the skill premium in Europe would increase. It is therefore the skill-biased technical change in the U.S. that is at the root of the labor-biased technical change and the declining skill premia in Europe.

The result in this subsection is quite extreme because there are only two kinds of goods, and their relative prices have to adjust to ensure equilibrium in the technology sectors of both the U.S. and Europe. However, the force at work is general. To illustrate this, in the next section I will use a modified model with differentiated products.

Also notice that the assumption that the LDCs use U.S. technologies is important. World price adjusts to satisfy the U.S. technology equilibrium condition because Europe is small relative to the world economy, and that LDCs are using U.S. technologies rather that European ones. In practice, since U.S. technologies appear to be more advanced, it seems reasonable that the LDCs should use predominantly U.S. technologies.

\section{The Impact of Trade on Europe-A Modified Model}

I now use a modified model where trade is a mixture of Ricardian and HeckscherOhlin to analyze the impact of trade on European technologies. The purpose of this analysis is to show that the results of the previous subsection are not special. Each different technology produces a slightly different variant of the same goods. The final good can be produced as in (2) as in the previous section, but since there are U.S. and European technologies, we now have :

$$
Y_{s}=\left[\left(Y_{s}^{U}+Y_{s}^{S}\right)^{\phi}+\left(Y_{s}^{E}\right)^{\phi}\right]^{1 / \phi}
$$

where $s=l, h$ and $Y_{s}^{S}$ is total supply from the South, and I have made use of the fact that all Southern countries employ U.S. technology. When there is no trade, this is equivalent to the formulation in the Section II. If $\phi=1$ (i.e. if elasticity of substitution 
is infinity), then we have a pure Heckscher-Ohlin world as in the previous subsection. Generally $\phi>\rho$, so that labor-intensive goods produced in different countries are good but imperfect substitutes, and the same for skill-intensive products.

Relative product prices are now:

$$
p^{c} \equiv \frac{p_{h}^{c}}{p_{l}^{c}}=\frac{\gamma\left(Y_{h}\right)^{\rho-\phi}\left(Y_{h}^{c}\right)^{-(1-\phi)}}{\left(Y_{l}\right)^{\rho-\phi}\left(Y_{l}^{c}\right)^{-(1-\phi)}}
$$

Due to the Ricardian elements, product prices now differ across countries. Using (3), (6) and profit-maximizing technology choice implies:

$$
p^{c}=\gamma^{\beta \psi}\left(\frac{Y_{h}}{Y_{l}}\right)^{(\rho-\phi) \beta \psi}\left(\frac{Q_{h}^{c}}{Q_{l}^{c}}\right)^{-\beta(1-\rho) \psi}\left(\frac{H^{c}}{L^{c}}\right)^{-\beta(1-\rho) \beta \psi},
$$

where $\psi \equiv(1-(1-\beta) \phi)^{-1}$. Since market sizes for new technologies have not changed, equilibrium still requires (13) to hold in the U.S. and Europe.

Since (6) applies, the LDCs use U.S. technologies, and prices in the South and the U.S. are the same, we also obtain

$$
Y_{s}=\left[\left(\left(p_{s}^{U}\right)^{(1-\beta) / \beta} Q_{s}^{U}\left(N_{s}^{U}+\theta N_{s}^{S}\right)\right)^{\phi}+\left(\left(p_{s}^{E}\right)^{(1-\beta) / \beta} Q_{s}^{E} N_{s}^{E}\right)^{\phi}\right]^{1 / \phi} .
$$

Recall that I continue to assume that Europe is small relative to the world economy, i.e. $N_{s}^{E}$ is small relative to $N_{s}^{U}+\theta N_{s}^{S}$. Also again, denote the pre-trade BGP relative price in country $c$ by $\left(p^{c}\right)^{N T}$ and the post-trade BGP price by $\left(p^{c}\right)^{T}$. Then, equilibrium condition (13) requires that $\left(p^{c}\right)^{N T} \approx\left(p^{c}\right)^{T}$, for $c=U$ and $E$. Using (3) and (24), in the U.S. we have:

$$
\frac{Y_{h}}{Y_{l}} \approx\left(\frac{\left(\left(Y_{h}^{U} / Y_{l}^{U}\right)^{N T}\right)^{1-\rho}}{\left(\left(Y_{h}^{U} / Y_{l}^{U}\right)^{T}\right)^{1-\phi}}\right)^{1 /(\phi-\rho)},
$$

where the left-hand side is the ratio of the world aggregates given by (26).

Now $\left(Y_{h}^{U} / Y_{l}^{U}\right)^{N T}$ and $\left(Y_{h}^{U} / Y_{l}^{U}\right)^{T}$ are given by (6), and when Europe is small, $Y_{h} / Y_{l} \approx\left(p^{U}\right)^{T}\left[\left(Q_{h}^{U} / Q_{l}^{U}\right)^{T}\right]\left[\left(H^{U}+\theta H^{S}\right) /\left(L^{U}+\theta L^{S}\right)\right]$. Defining,

as before, $\left(\left(H^{U}+\theta H^{S}\right) /\left(L^{U}+\theta L^{S}\right)\right) \equiv \zeta\left(H^{U} / L^{U}\right)$ where $\zeta$ is naturally less than 1 , we have:

$$
\left(\frac{Q_{h}^{U}}{Q_{l}^{U}}\right)^{T}=\zeta^{(\rho-\phi) /(1-\rho)}\left(\frac{Q_{h}^{U}}{Q_{l}^{U}}\right)^{N T} .
$$


Since $\phi>\rho$, we have $\zeta^{(\rho-\phi) /(1-\rho)}>1$, and so trade causes skill-biased technical change in the U.S.. The reason for this induced skill-biased technical change is again the price effect on the direction of technical change. Equation (13) still applies because the market sizes for different technologies have not changed-intellectual property rights continue not to be enforced in the LDCs. Everything else equal, trade would increase the relative price of skill-intensive goods, and this will make skill-complementary innovations more profitable. This induced technical change effect is once again strong enough that the equilibrium productivity of skilled workers increases to leave the relative price of skillintensive goods unchanged.

Next, notice that if $\left(Y_{h}^{E} / Y_{l}^{E}\right)^{N T}=Y_{h} / Y_{l}$, then trade-opening will not affect the direction of technical change in Europe. That is, $\left(Q_{h}^{E} / Q_{l}^{E}\right)^{T}=\left(Q_{h}^{E} / Q_{l}^{E}\right)^{N T}$. But, if $\left(Y_{h}^{E} / Y_{l}^{E}\right)^{N T}>Y_{h} / Y_{l}$, then trade will also cause skill-biased technical change in Europe. In contrast, if $\left(Y_{h}^{E} / Y_{l}^{E}\right)^{N T}<Y_{h} / Y_{l}$, then trade causes labor-biased technical change in Europe. When will this condition be satisfied?

Straightforward algebra establishes that if

$$
\left(\frac{H^{U}}{L^{U}}\right) \zeta^{1 / \beta}>\left(\frac{H^{E}}{L^{E}}\right)
$$

then $\left(Y_{h}^{E} / Y_{l}^{E}\right)^{N T}<Y_{h} / Y_{l}$, and trade induces labor-biased technical change in Europe.

What happens to skill premia in different countries? Once again using supscripts $T$ and $N T$ to denote pre and post-trade values,

$$
\left(\omega^{U}\right)^{T}=\left(\omega^{S}\right)^{T}=\zeta^{(\rho-\phi) /(1-\rho)}\left(\omega^{U}\right)^{N T}
$$

So, skill premia in the U.S. necessarily increase. In the South, skill premia converge to the new U.S. skill premia. As in the previus subsection, whether they increase overall or not depends on their pre-trade values. In particular, recalling equation (17), we see that wage inequality will increase if

$$
\frac{H^{S_{j}}}{L^{S_{j}}}>\zeta^{\beta \rho(\phi-\rho) /(1-\rho)^{2}}\left(\zeta \frac{H^{U}}{L^{U}}\right),
$$

which is similar to the result obtained above. LDCs for which this inequality holds will experience an increase in inequality, while the rest will experience a decline. 
For Europe, we have

$$
\left(\omega^{E}\right)^{T}=\frac{\left(Q_{h}^{E} / Q_{l}^{E}\right)^{T}}{\left(Q_{h}^{E} / Q_{l}^{E}\right)^{N T}}\left(\omega^{E}\right)^{N T},
$$

so if (27) holds, inequality will decline in Europe. ${ }^{16}$

Therefore, we find once again that trade may reduce inequality in Europe. The induced skill-biased technical change in the U.S. resulting from trade may improve the technologies used by U.S. and LDC skilled workers sufficiently to reduce the relative price of skill-intensive goods in Europe, encouraging labor-biased technical change there. Although this result needs to be studied further, both theoretically and empirically, it offers a potential explanation for why the demand for skills appears not to have increased as much in Europe as in the U.S..

\section{Concluding Remarks}

This paper has constructed a model to analyze the patterns of skill premia we observe across countries and over time. Skill premia are determined by the relative supply of skills, the degree of skill bias in technology, and international trade. Skill bias is endogenous, determined by the relative profitability of developing different types of technologies. An increase in the number of skilled workers expands the market size for skill-complementary technologies, and induces skill-biased technical change. This increase in the demand for skills implies that skill premia may increase in response to an expanding supply of skilled workers. The relation between the relative supplies and skill premia across countries is quite different in nature, however. Among countries using the same technology, there will be a well defined negative relation between the relative supply of skills and the skill premium. In contrast, among countries developing their own technologies, the relation may be increasing. This may account for why the U.S. has higher inequality than European countries despite its greater supply of skills.

An important implication of this framework is that increased international trade will have an effect on skill premia by changing the nature of technologies that are being

\footnotetext{
${ }^{16}$ Since in Europe $H / L$ increased over this period, a positive value of $\eta$ would create a force towards a higher demand for skills. Overall, therefore, demand for skills in Europe may have increased over the past twenty years, but much less than in the U.S. where both the rise in $H / L$ and trade increased the demand for skills, which is consistent with the findings of Berman, Bound and Machin [1998].
} 
developed, as well as its more direct standard effect. Under most plausible circumstances, trade between the U.S. and the LDCs will induce skill-biased technical change in the U.S., and will cause a large increase in U.S. skill premia. Contrary to the standard models, this induced technology effect also implies that trade may increase skill premia in the LDCs.

The most speculative resuits of the paper concern the impact of trade on Europe. One of the puzzling developments over the past twenty years has been the stability of returns to schooling and wage inequality in many European economies, in the face of sharply increasing inequality in the U.S.. Although many economists believe that labor market institutions in Europe may be responsible for this, evidence for this hypothesis has been difficult to find. The institutional wage compression explanation predicts that if skill-biased technical change is a world-wide phenomenon, unskilled unemployment should have increased in Europe relative to skilled unemployment. This prediction receives no empirical support (see for example, Nickell and Bell [1995], Card, Kramartz and Lemieux [1995], Krueger and Pischke [1998]). So the reason may be that demand for skills has increased much less in Europe than in the U.S.. My model suggests a possible explanation. Trade may cause labor-biased technical change in Europe, contrary to its effect in the U.S.: most LDCs use U.S. technologies, and with the increased productivity of skilled workers both in the U.S. and in the LDCs following trade, the supply of skillintensive goods in the world economy may increase so much that their relative world price may be below their pre-trade European level. In this case, trade will cause laborbiased technical change in Europe, and will tend to reduce inequality there. Future theoretical and empirical research investigating this paradoxical result further may be useful. 


\section{References}

Acemoglu, Daron, "Why Do New Technologies Complement Skills? Directed Technical Change and Wage Inequality" Quarterly Journal of Economics, CXIII (1998), 1055-1090.

Acemoglu, Daron "Changes in Unemployment and Wage Inequality: An Alternative Theory and Some Evidence" forthcoming American Economic Review (1999).

Acemoglu, Daron and Fabrizio Zilibotti, "Productivity Differences" MIT Mimeo, 1998.

Aghion, Philippe and Peter Howitt, "A Model of Growth Through Creative Destruction" Econometrica, LX (1992), 323-351.

and Gianluca Violante, "Technology, Knowledge, and

Inequality" Harvard mimeo, 1999.

Ahmad, Syed, "On The Theory of Induced Invention," Economic Journal LXXVI, (1966), pp. 344-357.

Autor, David, Alan Krueger and Lawrence Katz, "Computing Inequality: Have Computers Changed the Labor Market?" Quarterly Journal of Economics, CXIII (1998), 1169-1214.

Atkinson, Anthony B. and Joseph E. Stiglitz (1969). "A New View of Technological Change," Economic Journal 79, 573-78.

Barro, Robert J. and Jong-Wha Lee "International Comparisons of Educational Attainment," Journal of Monetary Economics 32, (1993), 363-94.

Basu, Susanto and David N. Weil "Appropriate Technology and Growth," Quarterly Journal of Economics, CXIII, 1025-1054.

Berman, Eli, John Bound and Stephen Machin "Implications of Skill-Biased Technological Change: International Evidence," Quarterly Journal of Economics, CXIII (1998), 1245-1280.

Card, David, Francis Kramartz and Thomas Lemieux (1995); "Changes in the Relative Structure of Wages and Employment: A Comparison of the United States, Canada and France" Mimeo (1996).

Caselli, Francesco "Technological Revolutions" forthcoming American Economic Review (1999). 
David, Paul, Technical Choice, Innovation and Economic Growth: Essays on American and British Experience in the Nineteenth Century, London, Cambridge University Press, 1975.

Freeman, Richard "Demand For Education" Chapter 6 in Orley Ashenfelter and Richard Layard (editors) Handbook of Labor Economics, North Holland, Vol I (1986), 357-386.

Freeman, Richard and Lawrence F. Katz, "Introduction and Summary," in R. Freeman and L. Katz (eds.), Differences and Changes in Wage Structures, Chicago, IL: The University of Chicago Press, pp. 1-22.

Galor Oded and Daniel Tsiddon, "Technological Progress, Mobility and Economic Growth" American Economic Review, LXXXVII, pp 363-382.

Galor, Oded and Omer Maov (1998) "Ability Biased Technological Transition, Wage Inequality and Economic Growth" Brown University Mimeo.

Grossman, Gene and Elhanan Helpman, "Quality Ladders in the Theory of Growth" Review of Economic Studies, LIIX (1991), 43-61.

Greenwood, Jeremy and Mehmet Yorukoglu, "1974" Carnegie-Rochester Conference Series on Public Policy, XLVI (1997), 49-95.

Habakkuk, H. J., American and British Technology in the Nineteenth Century: Search for Labor Saving Inventions, Cambridge University Press, 1962.

Hanson, Gordon H. and Ann Harrison, "Trade Technology, and Wage Inequality: Evidence from Mexico," (September 1994), mimeo.

Hayami, Yujiro and Vernon Ruttan, "Factor Prices and Technical Change in Agricultural Development: the U.S. and Japan, 1880-1960" Journal of Political Economy, LXXII (1970), 1115-1141.

Katz Lawrence and Kevin Murphy, "Changes in Relative Wages: Supply and Demand Factors" Quarterly Journal of Economics, CVII (1992), 35-78.

Kennedy, Charles, "Induced Bias in Innovation and the Theory of Distribution" Economic Journal, LXXIV (1964), 541-547.

Krueger, Alan "Labor Market Shifts and the Price Puzzle Revisited" Princeton University, Industrial Relations Section Working Paper. No. 375, 1997.

Krueger, Alan B. and Jörn-Steffen Pischke "Observations and conjectures on the U.S. employment miracle," NBER Working Paper No. 6146, (1997). 
Krugman, Paul "Growing World Trade: Causes and Consequences" Brookings Papers on Economic Activity (1995), pp 327-377.

Krusell, Per, Lee Ohanian, Victor Rios-Rull and Giovanni Violante, "Capital Skill Complementary and Inequality", University of Rochester Mimeo, 1997.

Lawrence, Robert and Matthew Slaughter "Trade and U.S. Wages: Giant Sucking Sound or Small Hiccup?" Brookings Papers on Economic Activity, (1993) pp. 161-226.

Lawrence, Robert Z., "Trade, Mulitinationals, and Labor," NBER Working Paper No. 4836 .

Leamer, Edward E., "Trade, Wages and Revolving-Door Ideas," NBER Working Paper No. 4716.

Nickell Stephen and Brian Bell "The Collapse in Demand For the Unskilled and Unemployment Across the OECD" Oxford Review of Economic Policy Vol 11, (1996) pp 40-62.

Psacharopoulos, George, "Returns to Investment in Education: A Global Update," World Development Vol. 22, no. 9 (1994), pp 1325-1343.

Robbins, Donald J., "Trade and Inequality in Seven Developing Countries: Summary and Synthesis of Country Studies," (December 1995), mimeo.

Romer, Paul, "Endogenous Technological Change" Journal of Political Economy, IIC (1990), S71-S102.

Sachs, Jeffrey and Howard Shatz "Trade and Jobs in US Manufacuring" Brookings Papers on Economic Activity, (1994) pp. 1-84.

Salter W. E.G., Productivity and Technical Change, 2nd edition, Cambridge University Press, (1966) Cambridge, United Kingdom.

Samuelson, Paul, "A Theory of Induced Innovations Along Kennedy-Weisacker Lines" Review of Economics and Statistics, XLVII (1965), 444-464.

Schmookler, Jacob, Invention and Economic Growth, Cambridge, Harvard University Press, 1966.

Stewart, Frances, Technology and Underdevelopment, The Macmillan Press, Ltd., (1978) London, England.

Wood, Adrian, North-South Trade, Employment and Inequality: Changing Fortunes in a Skill Driven World, Oxford, Clarendon Press, 1994. 